\title{
Jeremia 52: Oordeel en hoop
}

\author{
H. de Waard
}

\begin{abstract}
This article examines the place and function of Jeremiah 52 in the book of Jeremiah, with a focus on the Masoretic text. It argues that the first part of Jeremiah 52, which describes the 587 BC fall of Jerusalem, shows how Jeremiah's judgment oracles were fulfilled-pre-exilic Judah collapsed completely. The second part of the chapter, which describes the 561 BC release of King Jehoiachin, alludes to the book's prophecies of hope for the exilic community in Babylon. From a biblical-theological perspective, this hope was partially realized in post-exilic Yehud; it has found and will find its full realization in the work of Christ.
\end{abstract}

Binnen het bijbelboek Jeremia heeft het laatste, $52^{\mathrm{e}}$ hoofdstuk een bijzondere plaats. Dat geldt niet alleen de positie aan het einde van het boek, maar meer nog de inhoud. Jeremia 52 bevat geen profetie, noch een verhaal over de profeet, maar een historisch verslag van de val van Jeruzalem in 587 v.Chr., gevolgd door een korte episode over de verhoging van koning Jojachin in Babel, enkele decennia later (561 v.Chr.). De bijzondere plaats van het hoofdstuk wordt, althans in de masoretische tekstvorm van het boek, ${ }^{1}$ gemarkeerd aan het einde van Jeremia 51. Daar geeft de frase 'Tot zover de woorden van Jeremia' (51:64) aan dat het eigenlijke profetenboek ten einde is (vgl. Jer. 1:1) en dat Jeremia 52 daar dus buiten valt.

In dit artikel wil ik laten zien dat Jeremia 52 niettemin een belangrijk en betekenisvol onderdeel van het boek Jeremia is. Het hoofdstuk vormt een postscriptum, dat duidelijk maakt hoe enerzijds Gods oordeel zich realiseerde, maar hoe dat anderzijds voor zijn volk toch niet het absolute einde bete-

1 Zie daarover $\$ 1$ hieronder. 
kende. ${ }^{2}$ Zo licht er ook in dit slothoofdstuk van Jeremia iets op van het heil dat uiteindelijk in Christus werkelijkheid wordt.

\section{Bewerkingen en tekstvormen}

Jeremia 52 vertoont grote overeenkomst met 2 Koningen 25 en is daar, volgens de gebruikelijke en mijns inziens juiste visie, van afgeleid. ${ }^{3}$ De daarvoor verantwoordelijke redacteur heeft echter verschillende wijzigingen doorgevoerd, om het hoofdstuk aan te passen aan zijn nieuwe context en aan de bedoeling die de redacteur met het hoofdstuk had. Juist deze wijzigingen zijn daarom van groot belang om de plaats en functie van Jeremia 52 binnen het boek Jeremia op het spoor te komen; de belangrijkste worden in $\$ 3$ en $\$ 4$ hieronder besproken.

Een ander belangrijk gegeven is dat er twee verschillende tekstvormen van Jeremia 52 bestaan. Net als in de rest van het boek zijn er forse verschillen tussen de masoretische tekst (MT) en de oude Griekse vertaling (LXX). Er zijn sterke redenen om aan te nemen dat de LXX gebaseerd is op een van MT afwijkende Hebreeuwse Vorlage, die (in de meeste gevallen) een oudere versie van het boek vertegenwoordigt. ${ }^{4}$ Waar Jeremia 52 LXX afwijkt van MT, weerspiegelt de Griekse tekst dus gewoonlijk de meer oorspronkelijke vorm

2 Dit artikel is gebaseerd op mijn dissertatie, waarop ik op 26 april 2019 promoveerde aan de Theologische Universiteit Apeldoorn en die (in licht aangepaste vorm) is uitgegeven onder de titel Jeremiah 52 in the Context of the Book of Jeremiah, VTSup 183, Leiden/Boston 2020. Jeremia 52 is een hoofdstuk waar relatief weinig onderzoek naar is gedaan, met uitzondering van de in $\$ 1$ hieronder besproken tekstuele kwesties. Veel aandacht voor de plaats en functie van Jeremia 52 binnen het boek Jeremia is er wél in het werk van Georg Fischer; diens belangrijkste publicatie op dit punt is 'Jeremia 52: Ein Schlüssel zum Jeremiabuch', in: id., Der Prophet wie Mose. Studien zum Jeremiabuch, BZABR 15, Wiesbaden 2011, 42-63; zie verder ook bijv. id., Jeremia 26-52, HThKAT, Freiburg im Breisgau 2005, 637-39. Mijn eigen conclusies wijken op diverse punten af van die van Fischer. Vanwege de beschikbare ruimte is er in dit artikel echter weinig expliciete discussie met Fischer en anderen; zie daarvoor mijn dissertatie.

3 De paralleltekst is, om precies te zijn, 2 Koningen 24:18-25:21, 27-30, maar wordt kortheidshalve aangeduid als 2 Koningen 25. Dat het hoofdstuk oorspronkelijk het slot van het Koningenboek vormde en vervolgens in het boek Jeremia is opgenomen (en bijv. niet andersom), blijkt uit de inhoudelijke en structurele inbedding in het geheel van Koningen. Zie bijvoorbeeld de nauwe relatie tussen 2 Koningen 25:13-17 en 1 Koningen 7.

4 Zie voor deze kwestie in het algemeen A. Huijgen en H. de Waard, 'Twee versies van Jeremia en een gereformeerde visie op de Schrift', Theologia Reformata 60 (2017), 143-60. 
van het hoofdstuk. De masoretische tekstvorm is het resultaat van latere bewerkingen. ${ }^{5}$

De belangrijkste van deze latere bewerkingen in Jeremia 52 was een harmonisatie met 2 Koningen 25.6 Deze harmonisatie zorgde ervoor dat de wijzigingen die de oorspronkelijke redacteur van Jeremia 52 had aangebracht, gedeeltelijk weer ongedaan gemaakt werden. Zoals blijkt uit de Griekse tekst van Jeremia 52, was 2 Koningen 24:19-20 aanvankelijk niet in Jeremia 52 overgenomen en had de redacteur van Jeremia 52 ook de verwijzingen naar de wegvoering van 587 v.Chr. (2 Kon. 25:11 en 21) weggelaten. Deze elementen ontbraken dus in de oorspronkelijke Hebreeuwse tekstvorm van Jeremia 52 , maar zijn in de masoretische tekstvorm ingevoegd vanuit 2 Koningen 25 (zie Jer. 52:2-3, 15 en 27).

Door deze en andere bewerkingen (zowel in Jer. 52 als elders in het boek) heeft Jeremia 52 in de masoretische tekstvorm niet precies dezelfde plaats en functie als in de oudere, door de LXX vertegenwoordigde tekstvorm. Omdat de masoretische tekstvorm in de kerk van het Westen, inclusief de protestantse traditie, echter de gebruikelijke is, zal die tekstvorm in dit artikel centraal staan. Wel zal ik belangrijke verschillen met de door de LXX vertegenwoordigde tekstvorm kort bespreken in kleine letter.

\section{De plaats van Jeremia 52 binnen de structuur van het boek Jeremia}

Het aan Jeremia 52 voorafgaande deel van het boek Jeremia (dus hoofdstuk 1-51) bestaat uit drie gedeelten, met elk een eigen karakter. Hoofdstuk 1-25 bevat een breed scala aan profetieën over Israël en Juda, die meest ongedateerd zijn. In hoofdstuk 26-45 zijn de profetieën veelal ingebed in verhalen over de profeet Jeremia en daarmee in een duidelijke historische setting. In hoofdstuk 46-51 zijn Jeremia's volkenprofetieën te vinden, die spreken over Gods handelen met andere volken dan Israël of Juda.

Over de samenhang van deze gedeelten en de precieze ordening van het materiaal binnen elk gedeelte is veel discussie. Duidelijk is echter dat, in de structuur van het boek, de hoofdstukken 1, 25 en 50-51 een belangrijke plaats

5 Voor een gedetailleerde bespreking van alle verschillen tussen de MT en de LXX van Jeremia 52 (alsmede van de relatie tussen Jer. 52 en 2 Kon. 25), zie De Waard, Jeremiah 52, 33-95.

6 De duidelijkste aanwijzing voor een dergelijke harmonisatie zijn enkele zogenaamde "dubbele lezingen" in Jeremia 52 MT. Daarbij combineert de masoretische tekstvorm de lezing van de door de LXX vertegenwoordigde (oudere) tekstvorm met een variante lezing uit 2 Koningen 25. Zie bijvoorbeeld Jeremia 52:34, waar de MT zowel 'tot de dag van zijn dood' (LXX) als 'al de dagen van zijn leven' (2 Kon. 25:30) heeft. 
hebben. ${ }^{7}$ Jeremia 1 vormt de proloog of inleiding van het boek, waarin veel belangrijke thema's reeds aan de orde komen. In het midden van het boek functioneert Jeremia 25 als een scharnierpunt. Het wijst terug naar het begin (25:3; vgl. 1:2), maar ook vooruit, naar de volkenprofetieën en de ondergang van Babel (25:12-38). De grote profetie over Babels ondergang in Jeremia 50-51 vormt de climax van het boek. JHWH gebruikte Babel weliswaar om Juda te straffen, maar uiteindelijk zal deze kwade macht zelf ten onder gaan.

$\mathrm{Na}$ dit alles heeft Jeremia 52, helemaal aan het einde van het boek, een wat geïsoleerde positie. Terwijl 1:1 het boek karakteriseert onder de titel 'De woorden van Jeremia', treffen we in hoofdstuk 52 noch de profeet, noch diens woorden aan. Inderdaad geeft, zoals aan het begin van dit artikel reeds aangeduid, 51:64 expliciet aan dat Jeremia 52 niet tot deze collectie van 'woorden van Jeremia' behoort. Bovendien komt het hoofdstuk nog ná de eigenlijke climax van het boek, de profetie tegen Babel in hoofdstuk 50-51.

In de LXX-tekstvorm heeft Jeremia 52 een wat minder geïsoleerde positie. In die tekstvorm staan de volkenprofetieën in het midden van het boek (na 25:13) en vormt de collectie verhalen in Jeremia 26-45 het derde gedeelte van het boek (hoofdstuk 33-51). Jeremia 52 sluit, als verhalende tekst, goed aan op deze collectie, temeer omdat het daar ook veel inhoudelijke verbindingen mee heeft. Door de andere plaats van de volkenprofetieën heeft het boek in de LXX-tekstvorm bovendien geen duidelijke, aan Jeremia 52 voorafgaande climax en ook ontbreekt aan het einde van hoofdstuk 51 de afsluitende frase 'Tot zover de woorden van Jeremia.' Niettemin onderscheidt Jeremia 52 zich ook in de LXX-tekstvorm door het ontbreken van enige verwijzing naar de profeet of zijn boodschap.

Hoewel Jeremia 52 dus buiten de hoofdstructuur van het boek staat, zijn er wel verbindingen te zien met de inleiding van het boek, Jeremia 1. De belangrijkste link tussen beide hoofdstukken wordt gevormd doordat het opschrift van het boek aangeeft dat Jeremia's profetische bediening duurde 'totdat Jeruzalem in de vijfde maand in ballingschap ging' (1:3). Aangezien Jeremia 40-44 verhaalt over Jeremia's bediening ná dat moment, is dit een opmerkelijke terminus ad quem, die echter, reeds aan het begin van het boek, het centrale belang van de val van Jeruzalem aangeeft. ${ }^{8}$ Uiteindelijk wordt dan in

7 Zie bijv. Martin Kessler, 'The Scaffolding of the Book of Jeremiah', in: id. (red.), Reading the Book of Jeremiah. A Search for Coherence, Winona Lake 2004, 57-66.

8 Wellicht werd het opschrift oorspronkelijk geformuleerd voor een versie van het boek waarin Jeremia 40-44 nog niet was opgenomen. 
Jeremia 52, helemaal aan het einde van het boek, de meest uitgebreide beschrijving van deze gebeurtenis gegeven (inclusief de datering in de vijfde maand'; 52:12; vgl. 39:1-10). Op deze manier ligt er een duidelijke verbinding tussen Jeremia 1 en Jeremia 52. ${ }^{9}$ Dat is een eerste indicatie dat Jeremia 52, ondanks zijn geïsoleerde positie, inhoudelijk in nauw verband staat met de rest van het boek.

De verbinding tussen 1:3 en Jeremia 52 is in de LXX-tekstvorm minder duidelijk. In die tekstvorm ontbreken in Jeremia 52 de verwijzingen naar de wegvoering van 587 v.Chr., zodat het hoofdstuk niet verhaalt hoe Jeruzalem 'in ballingschap ging'. Toch is de verbinding tussen 1:3 en Jeremia 52 in de LXXtekstvorm niet afwezig, aangezien de desbetreffende frase in 1:3 associaties oproept met de rampspoed van 587 v.Chr. in het algemeen. Dáárvan geeft Jeremia 52 ook in de LXX-tekstvorm een indrukwekkend getuigenis.

\section{De val van Jeruzalem (52:1-30) in de context van het boek Jeremia}

Het eerste en grootste gedeelte van Jeremia 52 beschrijft de val van Jeruzalem in 587 v.Chr. (vv. 1-30). Zoals 1:3 reeds aangeeft (zie boven), speelt deze gebeurtenis ook elders in het boek een belangrijke rol, vooral in het tweede gedeelte van het boek (hoofdstuk 26-45). De hoofdstukken 32-34 en 37-38 zijn gesitueerd tijdens het in 52:5-6 kort aangeduide beleg van Jeruzalem en bevatten diverse profetieën die de ondergang van de stad en haar bevolking aankondigen (zie ook 21:1-10). Hoofdstuk 37-38 zijn bovendien onderdeel van een groter verhaal, dat ook de inname en verwoesting van de stad beschrijft (39:1-14) en vervolgens de lotgevallen van het 'restant van Juda' dat wil zeggen: de bevolking die na 587 v.Chr. in het land achterbleef (40:144:30). In dit laatste gedeelte, over het 'restant van Juda', wordt verschillende malen teruggeblikt op de val van Jeruzalem en wordt deze gebeurtenis expliciet geduid als het strafoordeel van JHWH en de vervulling van Jeremia's profetieën (zie 40:2-3; 42:18; 44:2-6, 13, 21-23, 30).

Jeremia 52:1-30 komt dus, aan het einde van het boek, uitgebreid terug op

9 Een andere belangrijke verbinding tussen Jeremia 1 en Jeremia 52 wordt gevormd doordat 1:18 de profeet Jeremia voorstelt als "een versterkte stad, een ijzeren pilaar en bronzen muren" en zo een ironisch contrast creëert met de in Jeremia 52 beschreven ondergang van Jeruzalem. Zie De Waard, Jeremiah 52, 214-15. Deze verbinding is er overigens alleen in de masoretische tekstvorm, aangezien in de (oudere) LXX-tekstvorm van 1:18 de frase 'een ijzeren pilaar' ontbreekt, terwijl juist deze frase een duidelijke link met Jeremia 52 legt (de pilaren van de tempel krijgen in 52:17-23 veel aandacht; elders in het boek is van pilaren alleen in 27:19 sprake). 
de gebeurtenis die eerder in het boek zo'n belangrijke rol speelt en in hoofdstuk 39 al (korter) beschreven werd. Het slothoofdstuk onderstreept op deze manier het belang en de impact van deze gebeurtenis. Het door Jeremia aangekondigde oordeel van JHWH kwam inderdaad, en het was verwoestend. ${ }^{10}$

Jeremia 39 LXX mist de verzen 1-2 en 4-13. De LXX-tekstvorm verwijst daardoor in Jeremia 39 slechts zijdelings naar de inname van Jeruzalem (39:3; zie ook 38:28) en biedt geen verslag van de verwoesting van de stad. Daardoor heeft Jeremia 52 in deze oudere tekstvorm een iets andere functie. Het hoofdstuk beschrijft de centrale gebeurtenis van het boek niet opnieuw, maar geeft daarvan de enige beschrijving die in het boek te vinden is.

De in 52:1-30 beschreven rampspoed werd veroorzaakt door de Babyloniërs. Dat sluit nauw aan bij een lijn die in het hele boek te vinden is, namelijk dat JHWH Nebukadnessar en zijn legers in dienst nam om zijn oordeel over Juda (en de rest van de wereld) ten uitvoer te brengen. Jeremia 52 laat zien hoe de Babyloniërs zich richtten tegen Sedekia (vv. 8-11), tegen de hoofdstad Jeruzalem (vv. 12-14, 17-23) en tegen de bevolking van Juda (vv. 15-16, 24-30). De beschrijving is op diverse punten te verbinden met profetieën van Jeremia en andere elementen uit het boek. ${ }^{11}$

Het in 52:8-11 beschreven lot van Sedekia laat zich voor een belangrijk deel lezen als vervulling van wat de profeet aankondigde: Sedekia zou niet ontsnappen $(32: 4 ; 34: 3 ; 37: 17 ; 38: 18,23)$, maar zich moeten verantwoorden voor Nebukadnessar $(32: 4 ; 34: 3)$ en naar Babel gevoerd worden $(32: 5 ; 34: 3)$. Dat Sedekia's zonen gedood zouden worden en bij hemzelf de ogen uitgestoken, was niet door Jeremia aangekondigd, maar maakt duidelijk dat Sedekia's dynastie definitief ten einde was. Dat laatste wordt nog eens onderstreept door de slotzin van 52:11. Deze zin, die aangeeft dat Sedekia voor de rest van zijn leven in Babel gevangenzat, ontbreekt in 2 Koningen 25 en moet zijn toe-

10 Doordat Jeremia 52 een uitgebreider verslag geeft dan Jeremia 39, wordt sterker de totaliteit van de ondergang benadrukt. Van belang is bovendien dat Jeremia 39 nog een vervolg krijgt in het verhaal over het 'restant van Juda' in hoofdstuk 40-44. Volgens dat verhaal is de rampspoed pas compleet als het 'restant' ook ten onder is gegaan. Een dergelijk vervolg is er in Jeremia 52 niet, zodat daar de val van Jeruzalem meer nadruk krijgt als de beslissende gebeurtenis, die een totale ondergang bracht.

11 Dat Jeremia 52:1-30 de vervulling van Jeremia's oordeelprofetie beschrijft, is de gebruikelijke mening onder commentatoren. Dat wordt echter zelden concreet uitgewerkt en ook is er in de literatuur weinig aandacht voor de verschillen tussen beide tekstvormen van Jeremia 52 of voor die tussen Jeremia 52 en 2 Koningen 25. 
gevoegd door de redacteur van Jeremia 52. Opmerkelijk genoeg is juist deze zin in tegenspraak met een profetie van Jeremia, aangezien deze geprofeteerd had dat JHWH uiteindelijk een positieve wending in Sedekia's lot zou brengen (32:5; vgl. 34:4-5). Jeremia 52:11 geeft echter aan dat zo'n positieve wending er nooit gekomen is; Sedekia's veroordeling was definitief.

Volgens de LXX - en waarschijnlijk de Hebreeuwse Vorlage daarvan - werd Sedekia gevangen gezet in een 'molenhuis' (vgl. Richt. 16:21). De latere lezing 'huis van bezoekingen' in 52:11 MT (een unieke term, die niet zomaar 'gevangenis' [HSV] betekent) bedoelt waarschijnlijk de tegenspraak met 32:5 op te lossen, waar dezelfde Hebreeuwse wortel wordt gebruikt: pqd 'bezoeken'. Het verband van 32:5 impliceert duidelijk een positieve betekenis van deze wortel ('omzien naar'; zo terecht bijv. de HSV), maar pqd heeft elders ook vaak een negatieve betekenis ('straffen, vergelden'). Het brede betekenisveld van de wortel bood ruimte om de belofte te herinterpreteren als een bedreiging, die dan vervuld werd door Sedekia's verblijf in het 'huis van bezoekingen' (52:11). ${ }^{12}$

Ook een tweede toevoeging in Jeremia 52 (t.o.v. 2 Kon. 25) benadrukt dat de ondergang van Juda volledig was. In de beschrijving van Nebukadnessars wraak op Sedekia heeft de redacteur van Jeremia 52 een zin toegevoegd die aangeeft dat, behalve Sedekia's zonen, ook 'alle vorsten van Juda' werden afgeslacht (v. 10). Deze zin verwijst naar de Judese aristocratie, die in het boek Jeremia een prominente, maar zeer negatieve rol speelt (zie vooral 37:11-15; 38:1-6, 24-27). Jeremia 52:10 maakt duidelijk dat die rol definitief uitgespeeld was; de goddeloze vorsten kregen de straf die ze verdienden.

Vervolgens vertelt Jeremia 52 dat de Babyloniërs niets heel lieten van Jeruzalem: ze verbrandden de gebouwen, haalden de muren neer en plunderden de tempel (vv. 12-14, 17-23). Ook hiermee gingen talrijke profetieën van Jeremia in vervulling, waarin de profeet had aangekondigd dat Jeruzalem verwoest zou worden en dat zelfs JHWH's eigen tempel niet immuun was voor zijn oordeel. ${ }^{13}$ Ten opzichte van de brontekst (2 Kon. 25) voegt Jeremia 52

12 Voor de relatie tussen de belofte in 32:5 en de verschillende lezingen in 52:11 (en enige theologische reflectie op het onvervuld blijven van de belofte), zie Henk de Waard, 'Did YHWH "Visit" Zedekiah? Exegetical and Theological Notes on the Relationship between Jeremiah 32:5 and 52:11', in: Jaap Dekker en Gert Kwakkel (red..), Reading and Listening. Meeting One God in Many Texts, Eric Peels, ACEBT.S 16, Bergambacht 2018, 127-33.

13 Zie 9:11; 19:8; 21:10; 34,2,22; 37:8; 38:18 etc. (verwoesting van de stad); 22:1-7 (verwoesting van het koninklijk paleis); 7:14; 26:6 (verwoesting van de tempel); 27:16-22 (plundering van de tempelschatten). 
hier niets wezenlijks toe, hoewel 52:17-23 wel in nog meer detail de geplunderde tempelschatten beschrijft. ${ }^{14}$

Ten slotte toont Jeremia 52 ook de vervulling van Jeremia's profetieën over de ondergang van de bevolking van Juda. Van hen die het beleg en de inname van Jeruzalem overleefd hadden, werd een selecte groep, met onder andere diverse hooggeplaatste functionarissen, alsnog ter dood gebracht (52:24-27; vgl. profetieën als 15:2; $21: 7$ en 34:17-30). Het grootste deel van de bevolking van Jeruzalem werd echter gedeporteerd (52:15). Vers 27 stelt zelfs, heel algemeen, dat 'Juda' als geheel in ballingschap werd gevoerd (vgl. profetieën als 7:15; 8:3; 9:15; 10:18; 16:13 en 20:4).

Toch noemt 52:16 ook achterblijvers, die echter gekarakteriseerd worden als een marginale groep ('een deel van de armsten van het land'). Bovendien laat 52:16 zich lezen in samenhang met Jeremia 40-44, waarin uitgebreid wordt verhaald hoe er een einde kwam aan dit 'restant van Juda'. Ongehoorzaam aan het door Jeremia gesproken Godswoord, vluchtte deze groep en masse naar Egypte (zie vooral 43:5-7), een volledige ondergang tegemoet (42:7-22; 44:1-30).

Kortom: 52:1-30 is inhoudelijk nauw verbonden met talrijke andere passages in het boek Jeremia. Het gedeelte beschrijft de centrale gebeurtenis van het boek: de val van Jeruzalem, die zorgde voor de totale ondergang van het pre-exilische Juda. Zo werd het strafoordeel van JHWH werkelijkheid, dat door Jeremia was aangekondigd.

De twee tekstvormen van Jeremia 52 vertonen een belangrijk verschil in de beschrijving van het lot van de bevolking. Zoals hierboven al aangegeven (zie $\$$ 1), noemt de (oudere) LXX-tekstvorm de wegvoering van 587 v.Chr. niet. Deze tekstvorm suggereert daarentegen dat het grootste deel van de bevolking behoudens hen die volgens 52:24-27 omkwamen - in het land Juda achterbleef. Met andere woorden, volgens de LXX-tekstvorm gingen de meeste mensen behoren tot het 'restant van Juda', waarvan Jeremia 40-44 de ondergang verhaalt.

Deze alternatieve beschrijving van het lot van de bevolking wijst er mijns inziens op dat de oorspronkelijke redacteur van Jeremia 52 de geschiedenis interpreteerde in het licht van Jeremia 24 (vgl. 29:1-19). Dat hoofdstuk maakt, in het bekende visioen van de vijgenkorven, scherp onderscheid tussen de Judeeërs die reeds in 597 v.Chr. in ballingschap gingen (de eerste wegvoering)

14 Het is onzeker of de uitbreiding van de beschrijving van de tempelschatten aan de oorspronkelijke redacteur van Jeremia 52 toegeschreven moet worden. Bovendien is niet duidelijk of er een inhoudelijke motivatie aan de uitbreiding ten grondslag lag, of eenvoudigweg een streven om zo volledig mogelijk te zijn. Zie De Waard, Jeremiah 52, 168, 170 n. 58. 
en hen die toen met Sedekia in Juda waren achtergebleven. De eerste groep wordt heil toegezegd (24:5-7), de tweede een totale ondergang (24:8-10). Door in Jeremia 52 de verwijzingen naar de tweede wegvoering (van 587 v.Chr.) niet uit 2 Koningen 25 over te nemen, wilde de redacteur van Jeremia 52 waarschijnlijk het scherpe onderscheid tussen de twee in Jeremia 24 genoemde groepen handhaven. Dat, zoals 2 Koningen 25 verhaalt, een groot deel van Sedekia's onderdanen tot de ballingschapsgemeenschap ging behoren, is strikt genomen immers in tegenspraak met het in Jeremia 24 gemaakte onderscheid.

Door harmonisatie met 2 Koningen 25 vermeldt de masoretische tekstvorm van Jeremia 52 de tweede wegvoering wel. Ook de unieke (in 2 Kon. 25 en de LXX-tekstvorm van Jer. 52 ontbrekende) lijst met ballingen in 52:28-30 MT maakt duidelijk dat de ballingschapsgemeenschap bestond uit Judeeërs die op verschillende momenten naar Babel gevoerd waren. Op deze manier doorbreekt de masoretische tekstvorm het in Jeremia 24 gemaakte onderscheid tussen de ballingen van 597 v.Chr. en de andere Judeeërs. Tegelijkertijd blijft er ook in deze tekstvorm, in lijn met Jeremia 24, een duidelijk contrast bestaan tussen het rampzalige lot van het pre-exilische Juda (52:1-30) en hoopvolle vooruitzichten voor de ballingschapsgemeenschap (52:31-34; zie $\$ 4$ hieronder). Niet langer wordt deze gemeenschap echter opgevat als bestaande uit alleen de ballingen van 597 v.Chr., maar uit Judeeërs die op verschillende momenten naar Babel kwamen.

\section{De verhoging van koning Jojachin (52:31-34) in de context van het boek Jeremia}

$\mathrm{Na}$ alle rampspoed in het eerste gedeelte van het hoofdstuk, beschrijft het tweede gedeelte van Jeremia 52 een veel positievere gebeurtenis: de vrijlating en verhoging van koning Jojachin (vv. 31-34). Exegeten hebben er echter al vaak op gewezen dat Jojachins voorspoed wel duidelijk begrensd is. Hij keert niet terug naar Jeruzalem, zijn verheven zetel is niet de troon van David en hij sterft in Babel. ${ }^{15}$

Wanneer 52:31-34 gelezen wordt in de context van het boek Jeremia, treden in de eerste plaats juist deze minder positieve noties op de voorgrond.

15 Zie bijv. Donald F. Murray, 'Of All the Years the Hopes-or Fears? Jehoiachin in Babylon (2 Kings 25:27-30)', JBL 120 (2001), 260-63. Vanwege de intrigerende combinatie van positieve en minder positieve noties is er, vooral met betrekking tot de paralleltekst 2 Koningen 25:27-30, weinig eenstemmigheid bij exegeten over de bedoeling van deze korte perikoop. Voor een kort overzicht van verschillende interpretaties, zie Murray, a.w., 245-47. Jeremia 52:31-34 wordt evenwel doorgaans geïnterpreteerd als (voorzichtig) signaal van een hoopvolle toekomst voor de ballingen en/of het koningschap (zie onder). 
Het boek bevat in 22:24-30 namelijk een profetie over Jojachin, waarin met nadruk wordt aangekondigd dat de koning naar Babel gevoerd zal worden en daar zal sterven (vv. 24-27), en dat geen van zijn zonen ooit op Davids troon zal zitten (vv. 28-30). Jeremia 52:31-34 laat, ondanks de positieve toonzetting, zien dat deze oordeelsprofetie in vervulling is gegaan, in ieder geval voor zover het Jojachins deportatie naar en sterven in Babel betreft. Hierbij is van belang dat 52:34 met de frase 'tot de dag van zijn dood' specifiek op het 'daar zult u sterven' van 22:26 lijkt te zinspelen. ${ }^{16}$

Volgens sommigen dient Jojachins verhoging in 52:31-34 als een teken van hoop voor de davidische dynastie. ${ }^{17}$ Mijns inziens is, in het licht van 22:28-30, een dergelijke interpretatie van de perikoop problematisch. Weliswaar bevat het boek Jeremia enkele profetieën die duidelijk uitspreken dat deze dynastie toekomst heeft (zie vooral 23:1-6), maar 22:30 ontzegt het nageslacht van Jojachin nadrukkelijk het zitten op Davids troon. Hoewel het koningschap dus hersteld zal worden, ziet het boek Jeremia daarin geen rol voor Jojachin. ${ }^{18}$

Toch moet bij de interpretatie van 52:31-34 het accent vallen op de positieve dimensie van Jojachins vrijlating. De gebeurtenis contrasteert immers duidelijk met het onheil in 52:1-30 (vgl. vooral het lot van Sedekia) en de tekst benadrukt de hoge status die Jojachin kreeg (vv. 32-33). Binnen het boek Jeremia kan deze positieve dimensie verbonden worden met de hoopvolle vooruitzichten die de profeet biedt aan de ballingschapsgemeenschap in Babel.

JHWH had Jeremia niet alleen aangesteld om 'weg te rukken, af te breken, te vernielen en omver te halen,' maar ook om 'te bouwen en te planten' (1:10) - behalve oordeel, mocht de profeet ook heil aankondigen. ${ }^{19}$ Een belangrijke aspect van de heilsprediking in het boek Jeremia is nu dat die primair geadresseerd is aan de ballingen in Babel. JHWH's oordeel brengt de ondergang van

16 Zie De Waard, Jeremiah 52, 148, 169-70. Mijns inziens heeft de redacteur van Jeremia 52 doelbewust de afsluitende frase 'al de dagen van zijn leven' (2 Kon. 25:30) veranderd in 'tot de dag van zijn dood' (zo Jer. 52:34 LXX) om een link te leggen met Jeremia 22:26. In Jeremia 52:34 MT is ook 'al de dagen van zijn leven' weer toegevoegd (vanuit 2 Kon. 25:30); zie n. 6 hierboven.

17 Bijv. Matthew H. Patton, Hope for a Tender Sprig: Jehoiachin in Biblical Theology, BBRSup 16, Winona Lake 2017, 75-81.

18 De paralleltekst in 2 Koningen 25:27-30 kan mijns inziens wél gelezen worden als hoopvol teken voor de davidische dynastie. Anders dan het boek Jeremia, keert het boek Koningen zich immers nergens expliciet tegen Jojachin en diens nageslacht.

19 De in 1:10 gebruikte werkwoorden hebben een belangrijke functie in het boek Jeremia, als kernachtige aanduidingen van JHWH's oordeel respectievelijk heil; zie ook 12:4-7; 18:7, 9; $24: 6 ; 31: 28,40 ; 42: 10 ; 45: 4$. 
het pre-exilische Juda, maar de ballingen wacht - na zeventig jaar-Gods heil (zie vooral Jer. 24 en 29:1-19). Mijns inziens zinspeelt Jojachins verhoging op dit toekomstperspectief voor de gemeenschap in Babel, die in het boek steeds nauw met Jojachin verbonden wordt $(24: 1 ; 27: 20 ; 28: 4 ; 29: 2)$. Ondanks JHWH's totale oordeel - zoals verhaald in 52:1-30 - loopt er toch een lijn naar de toekomst en wel via de ballingschapsgemeenschap. De in 52:31-34 verhaalde positieve gebeurtenis in Babel is daarvan een hoopvol teken. ${ }^{20}$

Zowel in Jeremia 24 als in 29:1-19 gelden de heilsbeloften de ballingen die in 597 v.Chr. met Jojachin naar Babel gedeporteerd werden (in contrast met Sedekia cum suis). Zoals hierboven besproken, bracht de redacteur van Jeremia 52 (die het hoofdstuk uit 2 Kon. 25 overnam) zijn tekst in lijn met dit perspectief door de verwijzingen naar de wegvoering van $587 \mathrm{v}$.Chr. weg te laten. De latere masoretische tekstvorm van Jeremia 52, waarin deze verwijzingen weer zijn ingevoegd en waarin ook de lijst met ballingen in vers 28-30 is opgenomen, is in overeenstemming met het feit dat de ballingschapsgemeenschap uiteindelijk bestond uit diverse groepen ballingen, die alle deelden in Jeremia's heilsbeloften.

\section{Conclusie en breder bijbels-theologisch perspectief}

Jeremia 52 valt buiten de hoofdstructuur van het boek Jeremia, maar is inhoudelijk nauw met het boek verbonden. Mijns inziens moet het hoofdstuk daarom gelezen worden als een uitgebreid postscriptum, dat duidelijk maakt hoe Jeremia's tweeledige boodschap van oordeel en heil (vgl. 1:10) betrekking heeft op onderscheiden Judese gemeenschappen. JHWH's oordeel geldt het pre-exilische Juda, dat inderdaad totaal ten onder ging. Hoop is er voor hen die naar Babel gevoerd waren. Via hen zou JHWH een nieuw begin maken.

Omdat Jeremia 52 in de LXX-tekstvorm een minder geïsoleerde positie heeft (zie boven) en ook meer dan in de masoretische tekstvorm functioneert als afsluiting van het boek, is voor de LXX-tekstvorm 'epiloog' wellicht de meest geschikte aanduiding voor Jeremia 52. De veelgebruikte term 'appendix/aanhangsel' is mijns inziens geen adequate aanduiding, omdat het hoofdstuk niet slechts aanvullende gegevens bevat, maar een inhoudelijk punt bedoelt te maken.

De verhoging van Jojachin, zoals verhaald in Jeremia 52:31-34, is dus een voorteken van meer - van het heil dat JHWH zou werken voor de Judeeërs in

20 Zie voor een bredere uitwerking De Waard, Jeremiah 52, 148-52. 
Babel. Dat heil kwam ook, toen er in de laatste decennia van de zesde eeuw v.Chr. ballingen naar Jeruzalem terugkeerden en daar een nieuw begin maakten (Ezra 1-6). Daarbij speelden uiteraard, net als bij de ondergang van Juda een halve eeuw eerder (vgl. Jer. 52:3), allerlei geopolitieke factoren een rol, maar theologisch (heilshistorisch) gezien was het JHWH die de gevangenen Sions terug deed keren (Ps. 126:1; zie ook bijv. 2 Kron. 36:22; Ezra 1:1). De enige reden voor deze verlossing lag bij God zelf: Hij had 'gedachten van vrede' (Jer. 29:11), die nergens anders toe te herleiden waren dan tot zijn soevereine liefde en trouw. ${ }^{21}$

De terugkeer van ballingen uit Babel en het nieuwe begin in Jeruzalem waren reële blijken van Gods onverklaarbare trouw aan zijn volk. Toch konden deze gebeurtenissen moeilijk gelden als de volledige vervulling van zijn rijke heilsbeloften. Toen de fundering van de tweede tempel gelegd was, was er, behalve lofprijzing en gejuich, ook geween (Ezra 3:11-13; vgl. Ps. 126:4-6). Bovendien ging het de eeuwen daarna meer achter- dan vooruit, zodat Daniël 9 de door Jeremia geprofeteerde periode van zeventig jaar ballingschap herïnterpreteert als zeventig jaarweken. De 'ballingschap' - dat wil zeggen, de situatie van onvolkomenheid en het niet (volledig) vervuld zijn van Gods beloften van herstel - duurde voort, lang nadat er in Jeruzalem weer een tempel stond. ${ }^{22}$

$\mathrm{Er}$ is dus een zekere analogie tussen de situatie van Gods volk in de postexilische periode en die van Jojachin aan het Babylonische hof: hoopvolle ontwikkelingen gaan gepaard met minder positieve noties. Ware het niet dat JHWH's heilsbeloften er toch liggen, dan zou, richting het einde van het Oude Testament, zelfs de vraag op kunnen komen of alles niet alsnog zal doodlopen (vgl. Jer. 52:34, in samenhang met 22:26). Die beloften geven echter grond om méér te verwachten en om uit de positieve ontwikkelingen, hoe begrensd of onvolkomen ook, toch hoop te putten.

In het Nieuwe Testament blijkt hoe JHWH inderdaad zijn heil doet komen. In Christus realiseert Hij het nieuwe verbond (Jer. 31:31-34; Luk. 22:20; 2 Kor. 3:6; Hebr. 8) en doet Hij zijn koninkrijk komen. Het werk van Christus, in het bijzonder zijn dood en opstanding, markeert een definitief

21 Vgl. H.G.L. Peels, 'Divine Forgiveness in the Book of Jeremiah', Unio cum Christo 5 (2019), 147-50.

22 Volgens N.T. Wright leefde dit idee van een 'continuing exile' breed binnen het jodendom van de (latere) tweede tempel-periode en is het daarom fundamenteel voor een goed verstaan van het Nieuwe Testament; zie bijv. Paul and the Faithfulness of God, Christian Origins and the Question of God 4, Minneapolis 2013, 139-63. Voor een (positieve) evaluatie van deze visie, zie Jacob J.T. Doedens, 'The Return of YHWH and the End of Exile', Sárospataki Füzetek 17 (2014), 27-53. 
keerpunt, hoewel Gods koninkrijk ook dan nog niet direct volkomen is. Door dat laatste - het 'nog niet' van het koninkrijk - vertoont ook de huidige heilshistorische situatie nog overeenkomsten met die van Jojachin en die van de post-exilische periode. Toch is er een fundamenteel verschil. Wij zien niet een verhoogde vazalkoning naast zijn suzerein in Babel, maar we zien Jezus, met heerlijkheid en eer gekroond, aan wie alle dingen onderworpen zijn (Hebr. 2:8-9). Dat is veel meer dan slechts een voorteken van toekomstig heil. Christus' verhoging is het bewijs dat het heil gerealiseerd is en garandeert dat zijn rijk spoedig volkomen zal zijn.

H. de Waard is docent Bijbels Hebreeuws en Aramees aan de Theologische Universiteit Apeldoorn. 